\title{
Aplikasi Mobile Your Job MBTI (Myers-Briggs Indicator) Menggunakan Algoritma Fisher-Yates Shuffle
}

\author{
Septi Andryana, Aris Gunaryati, Bimo Salasa Putra* \\ Fakultas Teknologi Komunikasi dan Informatika, Prodi Informatika, Universitas Nasional, Jakarta Selatan, Indonesia \\ Email: ${ }^{1}$ septi.andryana@ civitas.unas.ac.id, ${ }^{2}$ arisgunaryati@ civitas.unas.ac.id, ${ }^{3, *}{ }^{*}$ bimosp8@ gmail.com@gmail.com \\ Email Penulis Korespondensi: bimosp8@gmail.com
}

\begin{abstract}
Abstrak-Berkerja merupakan sebuah hal yang pasti akan dilakukan oleh setiap orang. Hal tersebut dikarenakan dengan bekerja kita akan mengahsilkan uang yang bisa membuat kita untuk bisa memenuhi kebutuhan hidup kita. Tetapi terkadang masih cukup banyak orang diluar sana bahkan tidak tahu pekerjaan apa yang cocok untuk dirinya. Maka dari itu penulis melakukan perancangan sebuah aplikasi yang bernama Your Job berbasis Android, aplikasi ini akan memberikan rekomendasi pekerjaan yang cocok berdasarkan kepribadian orang tersebut. Pada penelitian ini menggunakan algoritma fisher-yates shuffle. Algoritma fisher-yates shuffle dapat diterapkan pada pengacakan soal. Pada perancangan aplikasi ini juga menggunakan metode MBTI (Myers-Briggs Indicator) agar bisa mempermudah dalam menentukan kepribadian seseorang. Setelah dilakukannya ke beberapa orang mengenai aplikasi ini. Mereka memberikan respon yang sangat baik, sudah dapat dipastikan bahwa algoritma fisher-ystes shuffle ini berjalan dengan baik dalam pengacakan soal dan penggunaan metode MBTI tingkat keakuratannya hampir mencapai $100 \%$ akurat.
\end{abstract}

Kata Kunci: Algoritma Fisher-Yates Shuffle; Android; Bekerja; MBTI; Your Job

Abstract-Work is something that everyone will do. This is because by working we will earn money that can make us able to fulfill our needs. But sometimes there are still quite a lot of people out there who don't even know what job is right for them. Therefore the author designed an application called Your Job based on Android, this application will provide suitable job recommendations based on the person's personality. In this study using the fisher-yates shuffle algorithm. Fisher-Yates shuffle algorithm can be applied to randomization of questions. The design of this application also uses the MBTI (Myers-Briggs Indicator) method to make it easier to determine a person's personality. After doing it to several people about this application. They gave a very good response, it is certain that the fisher-ystes shuffle algorithm runs well in randomizing the questions and using the MBTI method the accuracy level is almost $100 \%$ accurate.

Keywords: Fisher-Yates Shuffle Algorithm; Android; MBTI; Work; Your Job

\section{PENDAHULUAN}

Berkerja merupakan sebuah hal yang nantinya akan dilakukan oleh setiap orang. Hal tersebut dikarenakan dengan bekerja kita akan mengahsilkan uang yang bisa membuat kita untuk bisa memenuhi kebutuhan hidup kita. Tetapi terkadang masih cukup banyak orang diluar sana bahkan tidak tahu pekerjaan apa yang cocok untuk dirinya. Pada akhirnya mereka yang belum tahu ingin bekerja atau pekerjaan seperti apa yang cocok oleh dirinya menjadi pengangguran yang bahkan berkepanjangan.

Dengan adanya permasalahan tersebut dibutuhkan aplikasi yang bisa membantu untuk menentukan pekerjaan apa yang cocok berdasarkan kepribadian orang tersebut, karena kepribadian sangat mempengaruhi efektifitas seseorang dalam melakukan pekerjaannya[1]. Penulis menawarkan aplikasi mobile dengan nama "Your Job", fungsi dari aplikasi ini memberikan rekomendasi pekerjaan yang cocok berdasarkan kepribadian orang tersebut yang dilakukan dengan menjawab tes soal yang telah diberikan.

Tes kepribadian merupakan tes yang dilakukan untuk dapat menedeskripsikan seseorang dalam bertingkah laku. Kepribadian adalah unik, sampai-sampai tidaklah bisa untuk dibandingkan dengan orang lain dalam mendeskripsikannya[2]. Ada begitu banyak tes kepribadian yang bisa dipakai dalam mencari tahu tentang kepribadian orang lain[3]. Namun pada penelitian kali ini akan dilakukan berdasarkan MBTI (Myers-Briggs Indicator). Sistem pada penelitian aplikasi ini dengan menggunakan algoritma fisher-yates shuffle, yang dimana algoritma tesebut seringkali dingunakan untuk pengackan soal dan algoritma ini ditujukan untuk mengacak soal dari pada tes kepribadian MBTI tersebut agar tidak memiliki pola yang serupa dan sama dengan orang lain saat melakukan tes.

Banyaknya penelitian terdahulu yang membahas tentang tes kepribadian MBTI dan algoritma fisher-yates shuffle, seperti pada penelitian Rio Priantama pada tahun 2019, dapat disimpulkan algoritma fisher-yates shuffle dapat diterapkan ke dalam aplikasi mobile sebagai pengacakan soal tidak berulang[4].

Selanjutnya pada penelitian Vihi Atina 2018,. Dalam penelitiannya penulis membuat sebuah aplikasi mobile tes kepribadian menggunakan metode MBTI yang ditujuan agar pengguna dapat memilih jurusan atau bidang kerja yang sesuai dengan kepribadian. Dalam penelitian tersebut disimpulkan bahwa validasi dari pada hasil tes MBTI yang telah dilakukan memiliki kesesuaian[5].

Selanjutnya pada penelitian MHD Arief Hasan 2017 Dalam penelitiannya penulis membuat aplikasi penerimaan mahasiswa baru dengan menggunakan algoritma fisher-yates shuffle. Dalam penelitian tersebut dikatakan bahwa dengan menerapkan algoritma fisher-yates shuffle pada aplikasi dapat mengacak soal dengan baik, dapat dilihat dari tampilan soal pada peserta ujian yang berbeda[6]. 
Selanjutnya pada penelitian Fachrul Kurniawa 2016. Dalam penelitiannya penulis membuat game dengan bahari yang menggunakan algoritma fisher-yates shuffle sebagai pengacak posisis NPC. Pada penelitian tesebut dikatakan bahwa algoritma fisher-yates shuffle digunakan bertujuan untuk mengacak array yang berisi gambar NPC dan hasilnya algoritma ini dapat berjalan sesuai dengan fungsinya untuk mengacak posisi NPC agar tidak posisinya berulang pada permainan berikutnya[7].

Berdasarkan penelitian tersebut, maka penulis akan membangun rancangan aplikasi berbasis android yang diberi nama "Your Job" dengan menggunakan algoritma fisher-yates shuflle. Dengan adanya aplikasi ini bertujuan untuk membantu dan mempermudah seseorang dalam menentukan pekerjaan apa yang cocok pada dirinya berdasarkan kepribadian yang dimiliki orang tersebut.

\section{METODOLOGI PENELITIAN}

Perancangan aplikasi ini memiliki bebrapa tahapan yang perlu untuk dilakukan . Berikut merupakan tahapantahapan yang perlu untuk dilakukan:

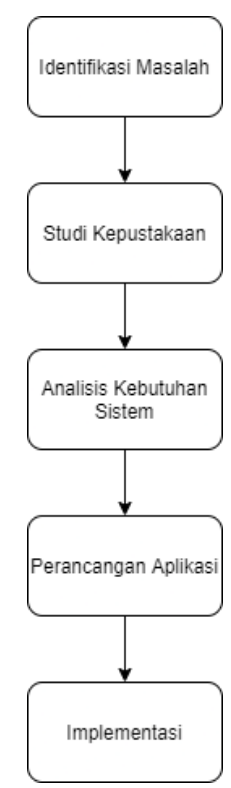

Gambar 1. Tahap-tahap Penelitian

Pada gambar 1 terdapat proses tahap-tahap pada penelitian, diantaranya adalah:

1. Identifikasi Masalah

Pengidentifikasian masalah pada penelitian ini diambil dari ketidak tahuan seseorang dalam mencari pekerjaan apa yang lebih cocok untuk dirinya sendiri. Maka dari itu penulis mencoba untuk mengatasinya dengan cara melakukan tes kepribadian dan merekomendasikan pekerjaan yang cocok berdasarkan kepribadian yang dimilikinya.

2. Studi Pustaka

Metode ini dilakukan dengan mengunmpulkan data-data yang terkait dengan MBTI, artikel-artikel serta literatur-litaratur tentang tes kepribadian dan aplikasi android.

3. Analisis Kebutuhan Sistem

Didalam analisis Kebutuhan ini merupakan proses pengumpulan informasi kebutuhan sistem atau perangkat lunak. Berikut merupakan hardware dan software yang digunakan oleh penulis dalam penelitian ini:
a. Processor : Intel(R) Core(TM) i7-5500U 2,4GHz
b. RAM
: $12 \mathrm{~GB}$
c. Hardisk : 500GB
d. Software : Android Studio, Adobe Ilustrator

4. Perancangan Aplikasi

Tahapan ini guna untuk membantu mempermudah dalam melakukan implementasi. Tahapan ini melakukan design aplikasi dan alur aplikasi.

5. Implementasi

Tahapan ini merupakan tahap dimana aplikasi telah selesai dibuat dan telah diterapkan algoritmafisheryates shuffle. 
Myers Briggs Type Indicator (MBTI) dikembangkan oleh Katharine Cook Briggs dan putrinya yang bernama Isabel Briggs Myer berdasarkan teori kepribadian dari Carl Gustav Jung. MBTI bersandar pada empat dimensi utama yang saling berlawanan (dikotomis)[5]. Walaupun berlawanan sebenarnya manusia memiliki semuanya, hanya saja lebih cenderung / lebih nyaman pada salah satu arah tertentu[8]. Empat dimensi utama MBTI:

1. Ekstrovert $(\mathrm{E})$ dan Introvert $(\mathrm{I})=$ melihat apakah orang tersebut lebih tertutup atau terbuka dengan orang lain.

2. Intuitive $(\mathrm{N})$ dan Sensing $(\mathrm{S})=$ melihat apakah orang tersebut lebih berfikir logis atau tidak logis.

3. Thinking $(\mathrm{T})$ dan Feeling $(\mathrm{F})=$ melihat apakah orang tersebut dalam pengambilan keputusan lebih menggunakan pikiran atau perasaan.

4. Judging $(\mathrm{J})$ dan Perceiving $(\mathrm{P})=$ melihat apakah orang tersebut dalam menghadapi sesuatu bisa secara fleksibel atau harus direncanakan.

Nantinya keempat kecenderungan tersebut dapat disimpulkan menjadi 16 kepribadian yang berbeda[9]. Dari keempat dimensi utama, maka tipe kepribadian seseorang dapat diketahui dan mengetahui pekerjaan apa yang cocok berdasarkan kepribadian yang dimilikinya[10].

Nama algoritma Fisher- Yates Shuffle diambil dari nama Ronald Fisher dan Frank Yates, yang juga dikenal sebagai Knuth Shuffle merupakan sebuah algoritma untuk menghasilkan permutasi acak dari suatu himpunan terhingga, dengan kata lain untuk mengacak suatu himpunan tersebut[11], [12]. Waktu eksekusi yang lebih cepat yang tidak memerlukan waktu yang lama untuk melakukan suatu pengacakan karena algoritma ini menggunakan memori yang minim menjadi sebuah alasan penting mengapa algoritma ini dipilih. Selain itu algoritma ini dalam proses pengacakan tidak ditemukan kemungkinan munculnya output yang sama[6].

Algoritma fisher-yates shuffle diusulkan pertamakali pada tahun 1938 dan dikaji pada tahun 1948 dengan versi modern yang disajikan dalam sebuh varian. Algoritma fisher-yates shuffle biasa dikenal juga dengan pengacakan knuth atau pengacakan fisher-yates-knuth[13].

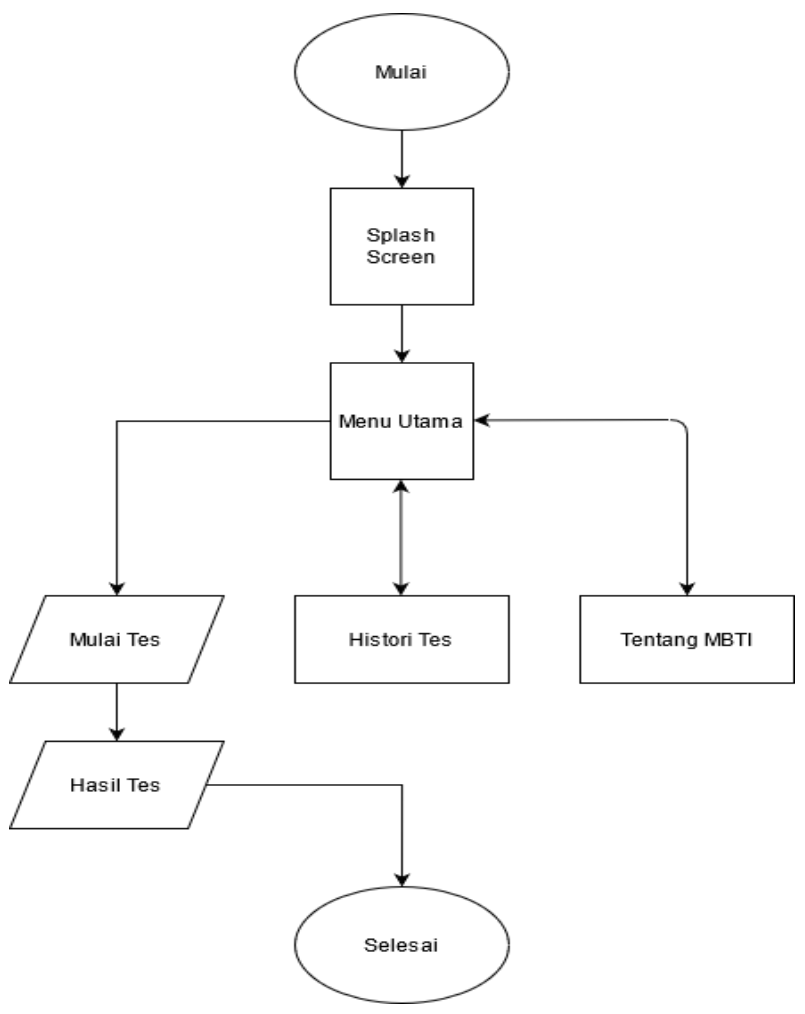

Gambar 2. Flowchart Aplikasi

Pada gambar 2 merupakan flowchart dari aplikasi Your Job, pada tahapan pertama akan menampilkan splash screen lalu menunjukan halaman utama. Pada halaman utama aplikasi terdapat menu untuk memulai tes, melihat history dari hasil tes, dan menu informasi tentang MBTI.

\section{HASIL DAN PEMBAHASAN}

Hasil dari pada penelitian dan perancangan yang telah dilakukan, maka penulis membangun sebuah aplikasi yang Android yang bernama Your Job. Aplikasi Your Job ini merupakan sebuah aplikasi yang bisa menentukan kepribadian seseorang berdasarkan hasil tes yang sudah dijalaninya, setelah itu aplikasi ini nantinya juga akan memberikan rekomendasi pekerjaan yang cocok berdasarkan kepribadian yang dimlikinya. 
ISSN 2614-5278 (media cetak), ISSN 2548-8368 (media online)

Available Online at https://ejurnal.stmik-budidarma.ac.id/index.php/mib DOI 10.30865/mib.v5i3.3095

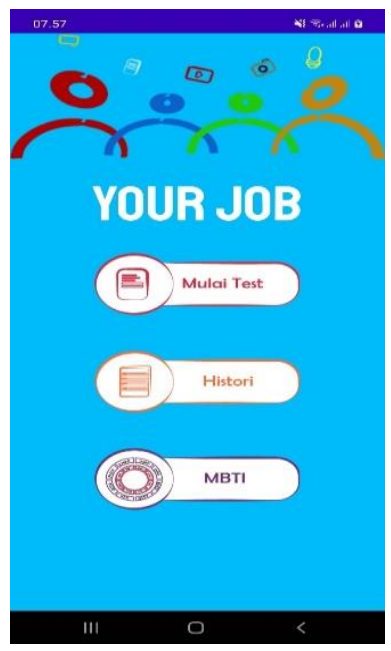

Gambar 3. Menu Utama Aplikasi

Menu utama pada gambar 3. Pada bagian menu ini terdapat logo aplikasi, mulai test, history, dan mbti. Tombol menu "mulai test" ini nantinya akan memulai dan memberikan soal secara acak. Pada tombol "histori" ini akan menampilkan kembali hasil tes yang sudah dijalani jika ingin melihatnya kembali, dan pada tombol "mbti" nantinya akan menampilkan 16 karakteristik yang ada pada mbti.

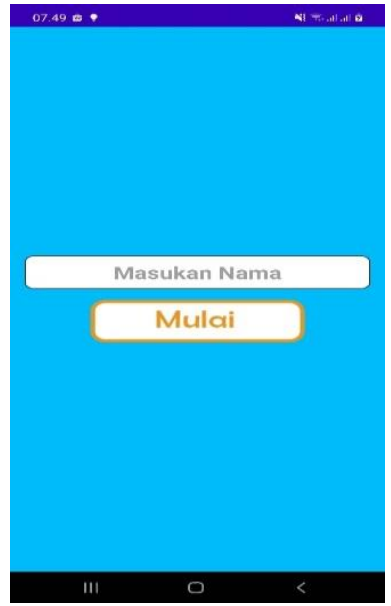

Gambar 4. Data Diri

Pada gambar 4 merupakan tampilan jika ingin memulai test. User akan diminta untuk memberikan data diri yang nantinya data diri tersebut akan digunakan pada menu histori untuk menampilkan hasil tes yang telah dijalaninya dan tidak tertukar.

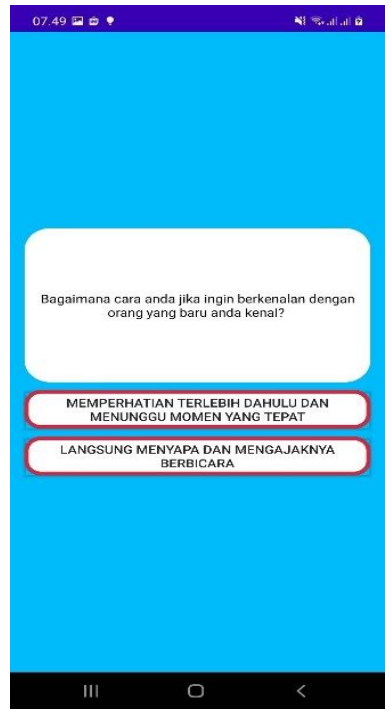

Gambar 5. Tampilan Soal Aplikasi

Septi Andryana, Copyright (C2021, MIB, Page 973 
ISSN 2614-5278 (media cetak), ISSN 2548-8368 (media online)

Available Online at https://ejurnal.stmik-budidarma.ac.id/index.php/mib DOI 10.30865/mib.v5i3.3095

Pada gambar 5 merupakan tampililan pada saat user melakukan tes mbti. Dengan menggunakan algoritma pengacakan fisher-yates shuflle ini tentu saja setiap user tidak akan mendapatkan pertanyaan yang sama, sehingga tes tersebut bisa benar-benar menilai berdasarkan kepribadian orang tersebut.

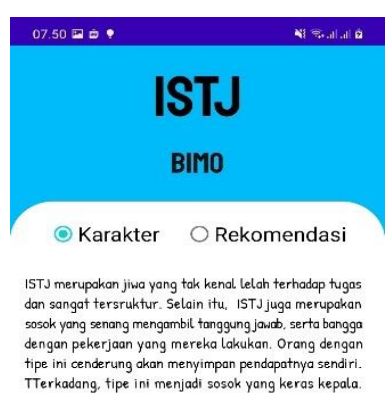

Gambar 6. Tampilan Hasil Aplikasi

Pada gambar 6 merupakan tampilan hasil dari pada tes yang telah dilakukan oleh user. Pada tempilan hasil ini nantinya akan menjelaskan tentang karakteristik ataupun kepribadian dari pada user dan juga memberikan rekomendasi pekerjaan yang cocok berdasarkan kepribadian yang dimilikinya[14].

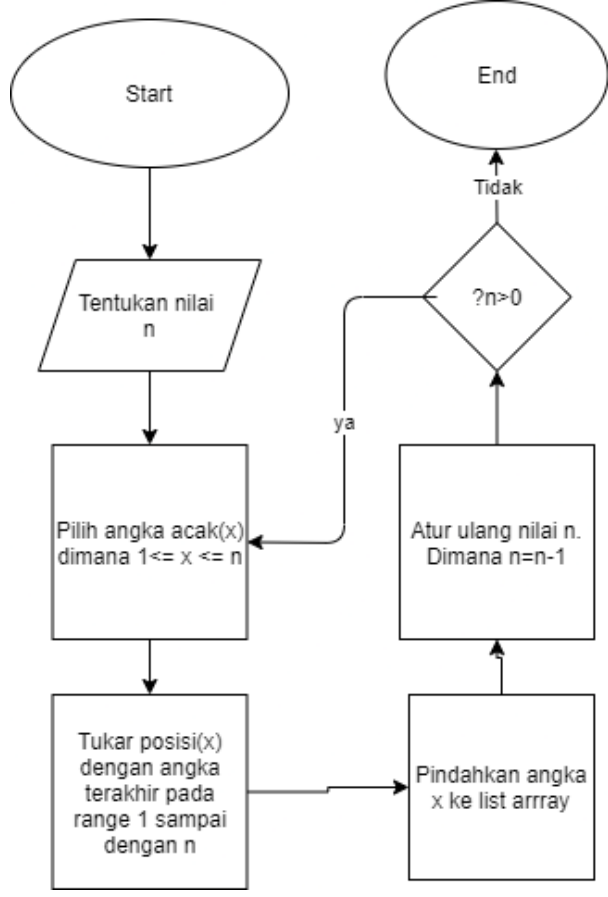

Gambar 7. Flowchart Algoritma Fisher-yates Shuffle

Gambar 7 merupakan flowchart algoritma fisher-yates shuffle. Menjelaskan bagaimana cara kerja dari algoritma fisher-yates shuffle, langkah awal yaitu dengan menentukan nilai x dan ditukar posisinya dengan angka terakhir sampai ke n, sehingga tidak terjadi perulangan. Metode fisher-yates shuffle modern yang sekarang biasa digunakan, angka yang terpilih tidak dicoret tetapi posisinya ditukar dengan angka terakhir dari angka yangbelum terpilih[15]. Berikut merupakan beberapa tahapan pada algoritma fisher-yates shuffle:
a) Menentukan $n$
b) Memilih angka acak (x) dimana $1<=\mathrm{x}<=\mathrm{n}$
c) Lalu pada range 1 - $\mathrm{n}$ ditukarkan dengan posisi ( $\mathrm{x}$ ) yang telah dipilih sebelumnya
d) Masukan x ke dalam list array
e) Mengatur ulang nilai $n$, dimana $n=n-1$ 
JURNAL MEDIA INFORMATIKA BUDIDARMA

Volume 5, Nomor 3, Juli 2021, Page 971-978

ISSN 2614-5278 (media cetak), ISSN 2548-8368 (media online)

Available Online at https://ejurnal.stmik-budidarma.ac.id/index.php/mib DOI 10.30865/mib.v5i3.3095

f) Jika $n$ masih memenuhi syarat yaitu $n>0$, maka melanjutkan kembali ke proses $b$

Jika sudah $\mathrm{n}=0$ maka proses pengacakan telah selesai dilakukan[11], [16].

Tabel 1. Pengujian Algoritma Fisher-yates

\begin{tabular}{|c|c|c|c|}
\hline Range & Roll & Scratch & Result \\
\hline & & $\begin{array}{l}1,2,3,4,5,6,7,8,9,10,11,12,13,14,15,16,17,18,19,20,21,22, \\
23,24,25,26,27,28,29,30,31,32,33,34,35,36,37,38,39,40\end{array}$ & \\
\hline $20-1$ & 26 & $\begin{array}{l}1,2,3,4,5,6,7,8,9,10,11,12,13,14,15,16,17,18,19,20,21,22 \\
23,24,25,40,27,28,29,30,31,32,33,34,35,36,37,38,39\end{array}$ & 26 \\
\hline $19-1$ & 6 & $\begin{array}{l}1,2,3,4,5,39,7,8,9,10,11,12,13,14,15,16,17,18,19,20,21, \\
22,23,24,25,40,27,28,29,30,31,32,33,34,35,36,37,38\end{array}$ & 6,26 \\
\hline $18-1$ & 30 & $\begin{array}{l}1,2,3,4,5,39,7,8,9,10,11,12,13,14,15,16,17,18,19,20,21, \\
22,23,24,25,40,27,28,29,38,31,32,33,34,35,36,37,38\end{array}$ & $30,6,26$ \\
\hline $17-1$ & 35 & $\begin{array}{l}1,2,3,4,5,39,7,8,9,10,11,12,13,14,15,16,17,18,19,20,21, \\
22,23,24,25,40,27,28,29,38,31,32,33,34,38,36,37\end{array}$ & $35,30,6,26$ \\
\hline $16-1$ & 36 & $\begin{array}{l}1,2,3,4,5,39,7,8,9,10,11,12,13,14,15,16,17,18,19,20,21 \\
22,23,24,25,40,27,28,29,38,31,32,33,34,38,37\end{array}$ & $36.35 .30,6,26$ \\
\hline $15-1$ & 39 & $\begin{array}{l}1,2,3,4,5,37,7,8,9,10,11,12,13,14,15,16,17,18,19,20,21 \\
22,23,24,25,40,27,28,29,38,31,32,33,34,38\end{array}$ & $39,36,35,30,6,26$ \\
\hline $14-1$ & 25 & $\begin{array}{l}1,2,3,4,5,37,7,8,9,10,11,12,13,14,15,16,17,18,19,20,21, \\
22,23,24,38,40,27,28,29,38,31,32,33,34\end{array}$ & $25,39,35,30,6,26$ \\
\hline $13-1$ & 32 & $\begin{array}{l}1,2,3,4,5,37,7,8,9,10,11,12,13,14,15,16,17,18,19,20,21, \\
22,23,24,38,40,27,28,29,38,31,34,33\end{array}$ & $32,25,39,35,30,6,26$ \\
\hline $12-1$ & 33 & $\begin{array}{l}1,2,3,4,5,37,7,8,9,10,11,12,13,14,15,16,17,18,19,20,21 \\
22,23,24,38,40,27,28,29,38,31,34\end{array}$ & $34,32,25,39,35,30,6,26$ \\
\hline $11-1$ & 11 & $\begin{array}{l}1,2,3,4,5,37,7,8,9,10,34,12,13,14,15,16,17,18,19,20,21, \\
22,23,24,38,40,27,28,29,38,31\end{array}$ & $11,34,32,25,39,35,30,6,26$ \\
\hline $10-1$ & 29 & $\begin{array}{l}1,2,3,4,5,37,7,8,9,10,34,12,13,14,15,16,17,18,19,20,21 \\
22,23,24,38,40,27,28,31,38\end{array}$ & $29,11,34,32,25,39,35,30,6,26$ \\
\hline $9-1$ & 13 & $\begin{array}{l}1,2,3,4,5,37,7,8,9,10,34,12,38,14,15,16,17,18,19,20,21, \\
22,23,24,38,40,27,28,31\end{array}$ & $\begin{array}{l}13,29,11,34,32,25,39,35,30 \\
6,26\end{array}$ \\
\hline $8-1$ & 34 & $\begin{array}{l}1,2,3,4,5,37,7,8,9,10,31,12,38,14,15,16,17,18,19,20,21, \\
22,23,24,38,40,27,28\end{array}$ & $\begin{array}{l}34,13,29,11,34,32,25,39,35 \\
30,6,26\end{array}$ \\
\hline $7-1$ & 27 & $\begin{array}{l}1,2,3,4,5,37,7,8,9,10,31,12,38,14,15,16,17,18,19,20,21 \\
22,23,24,38,40,28\end{array}$ & $\begin{array}{l}27,34,13,29,11,34,32,25,39 \\
35,30,6,26\end{array}$ \\
\hline 6-1 & 22 & $\begin{array}{l}1,2,3,4,5,37,7,8,9,10,31,12,38,14,15,16,17,18,19,20,21, \\
28,23,24,38,40\end{array}$ & $\begin{array}{l}22,27,34,13,29,11,34,32,25 \\
39,35,30,6,26\end{array}$ \\
\hline $5-1$ & 15 & $\begin{array}{l}1,2,3,4,5,37,7,8,9,10,31,12,38,14,40,16,17,18,19,20,21, \\
28,23,24,38\end{array}$ & $\begin{array}{l}15,22,27,34,13,29,11,34,32 \\
25,39,35,30,6,26\end{array}$ \\
\hline $4-1$ & 7 & $\begin{array}{l}1,2,3,4,5,37,38,8,9,10,31,12,38,14,40,16,17,18,19,20,21 \\
28,23,24\end{array}$ & $\begin{array}{l}7,15,22,27,34,13,29,11,34,32 \\
25,39,35,30,6,26\end{array}$ \\
\hline $3-1$ & 23 & $\begin{array}{l}1,2,3,4,5,37,38,8,9,10,31,12,38,14,40,16,17,18,19,20,21 \\
28,24\end{array}$ & $\begin{array}{l}23,7,15,22,27,34,13,29,11,34 \\
32,25,39,35,30,6,26\end{array}$ \\
\hline \multirow[t]{2}{*}{$2-1$} & 37 & $\begin{array}{l}1,2,3,4,5,24,38,8,9,10,31,12,38,14,40,16,17,18,19,20,21 \\
28\end{array}$ & $\begin{array}{l}37,23,7,15,22,27,34,13,29,11 \\
34,32,25,39,35,30,6,26\end{array}$ \\
\hline & 24 & $1,2,3,4,5,28,38,8,9,10,31,12,38,14,40,16,17,18,19,20,21$ & $\begin{array}{l}24,37,23,7,15,22,27,34,13,29 \\
11,34,32,25,39,35,30,6,26\end{array}$ \\
\hline
\end{tabular}

Pada tabel 1 merupakan hasil perhitungan manual proses pengacakan urutan soal menggunakan algoritma fisher-yates shuffle. Range merupakan angka yang belum terpilih, roll merupakan angka acak yang terpilih, scratch adalah daftar angka yang belum terpilih dan result adalah hasil permutasi acak yang akan didapat[17]. Dimana didapatkan soal terpilih sebanyak 20 buah dari 40 buah soal diantaranya adalah soal ke, 24, 37, 23, 7, 15, 22, 27 , $34,13,29,11,34,32,25,39,35,30,6,26$. Jika dimasukan kedalam rumus maka contoh singkatnya akan seperti: a. Nilai $x=24,37,23,7,15,22,27,34,13,29,11,34,32,25,39,35,30,6,26$

b. $\mathrm{n}=\{1,2,3,4,5,6,7,8,9,10,11,12,13,14,15,16,17,18,19,20,21,22,23,24,25,26,27,28,29,30$, $31,32,33,34,35,36,37,38,39,40\}$

c. Memilih angka acak (x) dimana $1<=\mathrm{x}<=\mathrm{n}$, misal $\mathrm{x}=26$

d. Lalu pada range $1-\mathrm{n}$ ditukarkan dengan posisi $(\mathrm{x})$ yang telah dipilih sebelumnya

e. Maka dari urutan awal $\{1,2,3, \ldots, 40\}$ akan berubah menjadi $\{1,2,3,4,5,6,7,8,9,10,11,12,13,14,15,16$, $17,18,19,20,21,22,23,24,25,40,27,28,29,30,31,32,33,34,35,36,37,38,39,26\}$

f. Pindahkan angka $\mathrm{x}$ ke isi array misalkan $\mathrm{t}=\{26\}$

g. Mengatur ulang nilas dimana nilai $\mathrm{n}=\mathrm{n}-1$, proses $\mathrm{n}-1$, maka yang akan diproses hanya $\{1,2,3,4,5,6,7,8,9$, $10,11,12,13,14,15,16,17,18,19,20,21,22,23,24,25,40,27,28,29,30,31,32,33,34,35,36,37,38$, 39\}

h. Jika $\mathrm{n}$ masih memenuhi syarat $\mathrm{n}>0$ maka akan kembali ke proses $\mathrm{b}$ dengan melakukan pilih angka acak $\mathrm{x}$ dimana $1<=\mathrm{x}<=\mathrm{n}$ 
ISSN 2614-5278 (media cetak), ISSN 2548-8368 (media online)

Available Online at https://ejurnal.stmik-budidarma.ac.id/index.php/mib DOI 10.30865/mib.v5i3.3095

i. Nilai n (n-1) Menjadi, 20-1 = 19

j. misal $x=6$, maka dari $\{1,2,3,4,5,39,7,8,9,10,11,12,13,14,15,16,17,18,19,20,21,22,23,24,25,40$, $27,28,29,30,31,32,33,34,35,36,37,38,39\}$ akan menjadi $\{1,2,3,4,5,6,7,8,9,10,11,12,13,14,15$, $16,17,18,19,20,21,22,23,24,25,40,27,28,29,30,31,32,33,34,35,36,37,38\}$

k. maka $\mathrm{t}=\{6,26\}$

1. Nilai n (n-1) Menjadi, $19-1=18$

m. Jika sudah $n=0$ maka proses pengacakan telah selesai dilakukan.

Tabel 2. List Soal

\begin{tabular}{ll}
\hline No & \\
\hline 1 & Saat dalam waktu libur anda lebih suka : \\
2 & Saat anda mengerjakan tugas... anda lebih suka : \\
3 & Saat anda dihadapkan dengan suatu masalah... anda lebih memilih untuk : \\
4 & Bagaimana cara anda jika ingin berkenalan dengan orang yang baru anda kenal? \\
5 & Dalam melakukan percakapan dengan orang lain kamu lebih suka : \\
6 & Jika kamu berada diruangan sendiri apakah kamu : \\
7 & Jika terjadi sebuah konflik diantara teman mu, yang kamu lakukan adalah : \\
8 & Kamu merupakan orang yang : \\
9 & Jika dikondisikan dalam sebuah kelas, kamu merupakan orang yang : \\
10 & Kamu lebih menyukai tempat : \\
\hline
\end{tabular}
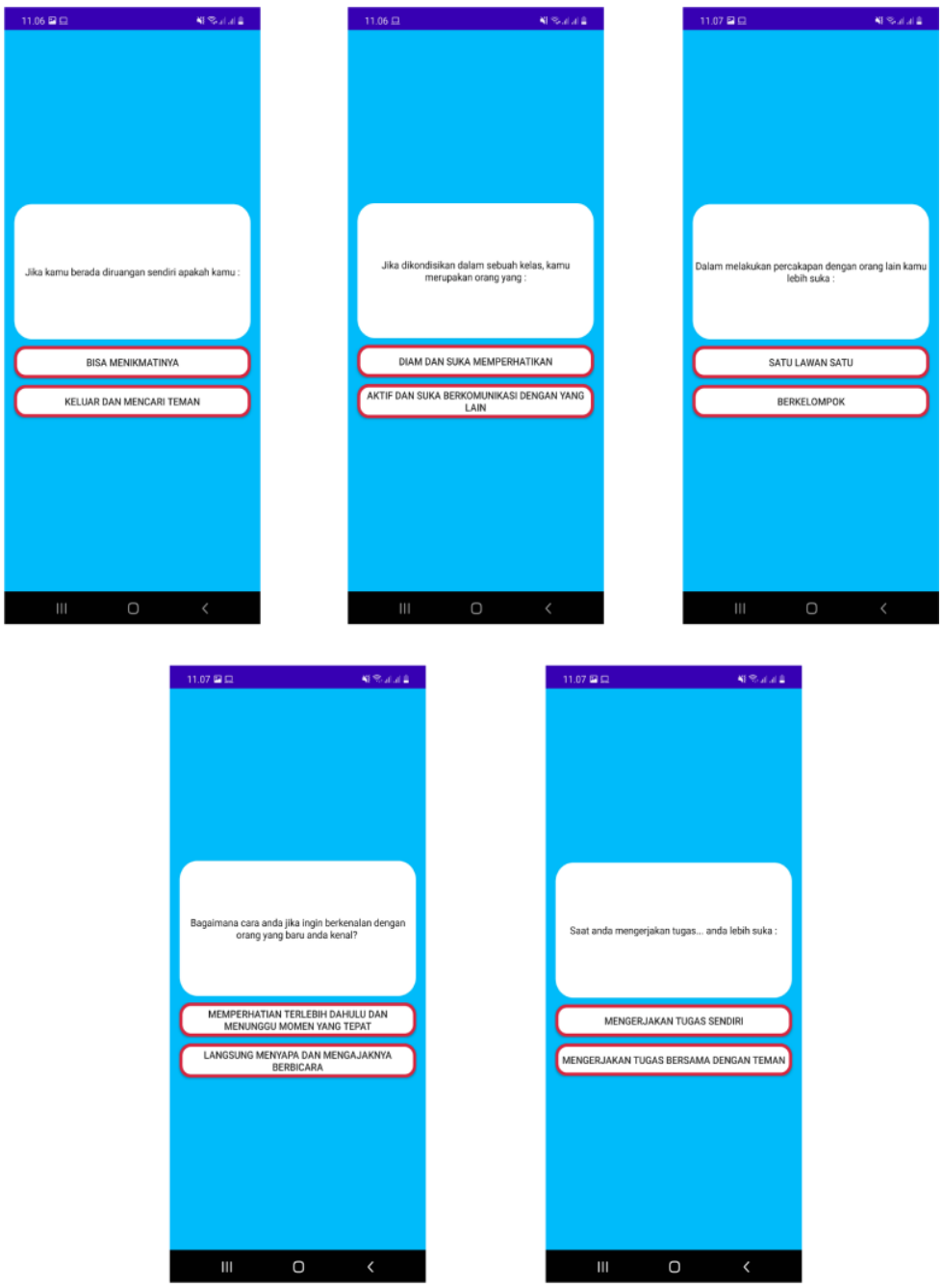

Gambar 8. Implementasi Algoritma Fisher-yates Shuffle

Implementasi dari pada algoritma fisher-yates shuffle yang ada pada gambar 8. Dari sedikit contoh list yang ada pada tabel 2, bisa disimpulkan bahwa dengan menggunakan algoritma fisher-yates shuffle sebagai pengacakan soal berjalan dengan baik dan tidak ada kemunculan soal yang sama atau tidak adanya perulangan. 
ISSN 2614-5278 (media cetak), ISSN 2548-8368 (media online)

Available Online at https://ejurnal.stmik-budidarma.ac.id/index.php/mib DOI 10.30865/mib.v5i3.3095

Tabel 3. Pengujian MBTI

\begin{tabular}{lc}
\hline Peserta & Tingkat Keak uratan \\
\hline Peserta 1 & $100 \%$ \\
Peserta 2 & $90 \%$ \\
Peserta 3 & $100 \%$ \\
Peserta 4 & $100 \%$ \\
Peserta 5 & $100 \%$ \\
Peserta 6 & $95 \%$ \\
Peserta 7 & $100 \%$ \\
Peserta 8 & $100 \%$ \\
Peserta 9 & $100 \%$ \\
Peserta 10 & $100 \%$ \\
\hline
\end{tabular}

Pada tabel 3 merupakan pengujian pada metode MBTI yang dilakukan oleh beberapa orang dan menilai apakah metode MBTI ini bisa digunakan dalam menentukan kepribadian. Dan seperti yang tertera pada tabel 3 , para peserta memberikan respon yang baik terhadap metode MBTI.

\section{KESIMPULAN}

Aplikasi Your Job ini merupakan aplikasi yang membantu seseorang dalam menentukan pilihan pekerjaan yang cocok pada dirinya berdasarkan kepribadian orang tersebut. Aplikasi ini menerapkan algoritma fisher-yates shuffle untuk pengacakan urutan soal dengan mengunakan metode MBTI (Myers-Briggs Indicator) untuk menentukan kepribadian orang tersebut. Melihat hasil penelitian dan hasil pengujian sudah dilakukan, aplikasi ini sudah bisa berjalan dengan baik, penerapan algoritma fisher-yates shuffle untuk pengacakan urutan soal berjalan dengan baik dan telah terbukti $100 \%$ setiap user tidak berkemungkinan mendapatkan urutan soal yang serupa maupun pengulangan soal. Dengan menggunakan metode MBTI untuk membaca kepribadian seseorang juga mendapatkan penilaian yang sangat bagus dari para penguji dengan tingkat keakuratan hampir $100 \%$.

\section{REFERENCES}

[1] I. N. Dost, G. Bohloulzadeh, and N. K. Hafshejani, "The Impact of Teachers' Personality on Senior High School EFL Learners' General English Achievement," Int. J. English Lit. Soc. Sci., vol. 2, no. 3, pp. 77-93, 2017, doi: 10.24001/ijels.2.3.9

[2] M. Agustina and D. Hurriyati, "Pengembangan Aplikasi Mobile Tes Kepribadian Andorid Berbasis," pp. 198-202, 2018.

[3] J. Andjarwirawan, A. Handojo, P. S. Informatika, F. T. Industri, U. K. Petra, and J. Siwalankerto, "Aplikasi Tes Kepribadian Online Berbasis Website pada Pusat Konseling dan Pengembangan Pribadi Universitas Kristen Petra," INFRA, vol. 7, pp. 1-4, 2019.

[4] R. Priantama and Y. Priandani, "Implementasi Algoritma Fisher Yates Untuk Pengacakan Soal Pada Aplikasi Mobile Learning Kuis Fiqih Berbasis Android," Nuansa Inform., vol. 13, no. 2, p. 40, 2019, doi: 10.25134/nuansa.v13i2.1951.

[5] V. Atina, F. E. Nastiti, and V. Aryadi, "Aplikasi Deteksi Kesesuaian Pekerjaan Berdasarkan Tes Kepribadian Berbasis Mobile,” J. Inf. Politek. Indonusa Surakarta, vol. 4, no. 3, pp. 1-6, 2018.

[6] M. A. Hasan, S. Supriadi, and Z. Zamzami, "Implementasi Algoritma Fisher-Yates Untuk Mengacak Soal Ujian Online Penerimaan Mahasiswa Baru (Studi Kasus : Universitas Lancang Kuning Riau)," J. Nas. Teknol. dan Sist. Inf., vol. 3, no. 2, pp. 291-298, 2017, doi: 10.25077/teknosi.v3i2.2017.291-298.

[7] F. Kurniawan, "Game Bahari Menggunakan Algoritma Fisher Yates Suffle Sebagai Pengacak Posisi NPC," Matics, vol. 7, no. 2, p. 71, 2016, doi: 10.18860/mat.v7i2.3281.

[8] I. Kaniawulan, M. R. Muttaqin, P. Studi, and T. Informatika, "Sistem Pakar Menentukan Jenis Pekerjaan Menggunakan Teori Myers-Briggs Type Indicator dengan Algoritma Forward Chaining,” no. 53.

[9] G. A. Ikhwanuddin, "Aplikasi Pengenalan Tipe Kepribadian Dengan Metode Mbti ( Myers - Briggs Type Indicator) Berbasis Computer Based Testing,” Univ. Islam Indones., 2017.

[10] H. Hanifa and M. Anwar, "Perancangan Sistem Pakar Tes Kepribadian Berdasarkan Teori Myers-Briggs Type Indicator Dengan Metode Forward Chaining Berbasis Android," Voteteknika (Vocational Tek. Elektron. dan Inform., vol. 6, no. 2 , p. 74, 2018, doi: 10.24036/voteteknika.v6i2.102023.

[11] Ekojono, D. A. Irawati, L. Affandi, and A. N. Rahmanto, "Penerapan Algoritma Fisher-Yates Pada Pengacakan Soal Game Aritmatika," Pros. SENTIA 2017 - Politek. Negeri Malang, vol. 9, no. ISSN: 2085-2347, pp. 101-106, 2017, [Online]. Available: http://sentia.polinema.ac.id/index.php/SENTIA2017/article/viewFile/237/225.

[12] K. Vebiant, M. I. Wahyuddin, and R. T. Komala Sari, "Rancang Bangun Media Pembelajaran Tenses English Berbasis Android menggunakan Algoritma Fisher-Yates," J. JTIK (Jurnal Teknol. Inf. dan Komunikasi), vol. 5, no. 4, p. 407, 2021, doi: 10.35870/jtik.v5i4.246.

[13] R. R. C. Putra and T. Sugihartono, "Penerapan Algoritma Fisher-Yates Shuffle pada Computer Based Test Ujian Sekolah di SMKN 1 Payung," MATRIK J. Manajemen, Tek. Inform. dan Rekayasa Komput., vol. 18, no. 2, pp. 276-283, 2019, doi: 10.30812/matrik.v18i2.399.

[14] A. N. Kusumastuti, Budiyono, and D. Indriati, "Mathematical internal connection ability based on personality types of sensing and intuiting," J. Phys. Conf. Ser., vol. 1806, no. 1, 2021, doi: 10.1088/1742-6596/1806/1/012093.

[15] W. A. Rohmah, A. Asriyanik, and W. Apriyandari, "Implementation of the Algorithm Fisher Yates Shuffle on Game 
JURNAL MEDIA INFORMATIKA BUDIDARMA

Volume 5, Nomor 3, Juli 2021, Page 971-978

ISSN 2614-5278 (media cetak), ISSN 2548-8368 (media online)

Available Online at https://ejurnal.stmik-budidarma.ac.id/index.php/mib DOI 10.30865/mib.v5i3.3095

Quiz Environment," J. Informatics Telecommun. Eng., vol. 4, no. 1, pp. 161-172, 2020, doi: 10.31289/jite.v4i1.3863.

[16] I. Maryono, W. B. Zulfikar, and R. Kariadinata, "The implementation of fisher yates shuffle on aljabar learning media based on hybrid application," MATEC Web Conf., vol. 197, pp. 1-5, 2018, doi: 10.1051/matecconf/201819701006.

[17] Y. Arviansyah, N. Nurfaizah, and R. Waluyo, "Penerapan Algoritma Fisher Yates Shuffle Pada Aplikasi TOEFL Preparation Berbasis Web,” J. Buana Inform., vol. 11, no. 2, p. 111, 2020, doi: 10.24002/jbi.v11i2.3622. 